\title{
Los Abetos de Luciano Lamberti
}

\author{
Lamberti, Luciano (2020).
}

Buenos Aires: China editora.

0

Daniel David Rosemberg Universidad de Buenos Aires, Argentina

Los Abetos (2020) es una novela de Luciano Lamberti cuyo tema principal es la vida de Samuel Beckett. Si bien un viejo refrán pide no juzgar los libros por sus portadas, partamos por allí. En este caso, la tapa elegida por China Editora (un dibujo -levemente caricaturesco- de la mitad del rostro del irlandés) parece una elección acertada, ya que el personaje es absolutamente reconocible, pero el texto no pretende dar una imagen completa, ni totalmente mimética.

La estructura del libro es, probablemente, el rasgo más sobresaliente, el cual lo aleja de una biografía lineal. Está dividido en cinco partes: "En el hospital"; "Enciclopedia Beckett", "Las últimas cintas", “Trabajo práctico” y “En el geriátrico”.

La primera abre con Beckett inmovilizado, en plena recuperación por el apuñalamiento recibido en 1938, del cual el lector no familiarizado se enterará luego. El primer adjetivo que el personaje recibe es “débil", esto sumado a su inmovilidad, lo acercan a algunos de sus personajes. También funciona así la paradójica situación de que la imposibilidad de hablar lo lleva a desear hacerlo, pese a que era un hombre silencioso. Se aprovecha esta falta de movimiento para explorar la interioridad del personaje. Un ejemplo lo vemos en la frase que, sin ser estilo indirecto, representa los pensamientos del autor de Molloy: "escribe el mismo libro en un inglés que quiere ser preciosista, único, cubriéndose de grandes palabras que no sirven para nada (...) el mismo Beckett, día tras día, una copia de sí mismo" (Lamberti, 2020:12). Beckett se autopresenta como un escritor fracasado, impublicable, casi maldito: "las editoriales que han cometido el error de publicarme enseguida quiebran, sus libros desaparecen, sus empleados se entregan al alcohol y empiezan a vivir en la calle" (ibid.: 16).

Las primeras palabras que Beckett dice son "Bibby. Bibby, nunca digo 'culo' " (ibid.:11). Parecen las palabras de un delirio producido por los sedantes, poco después, a través de una analepsis, se nos explicará el significado de esta frase, que lo retrae a la infancia.
En este capítulo veremos su relación con varios de los personajes fundamentales: James Joyce, Peggy Guggenheim (la pareja en aquel momento), Suzanne Déchevaux- Dumesnil (que la reemplazará en ese rol) y la madre, Mary Jones Roe. Detengámonos en algunos de ellos. El lector que no esté familiarizado con sus biografías puede sorprenderse (y acaso decepcionarse) con la escena en la que dos de los más grandes escritores del siglo XX (Beckett y Joyce) mantienen un largo silencio. El narrador nos explica que no se trata de un silencio incómodo, sino habitual en ellos.

Sobre la madre, con la que mantenía una mala relación, hay algunos monólogos que piden análisis psicoanalíticos: "yo soy Beckett y nunca nací. Todavía estoy en el vientre de mi madre" (ibid.:15). De hecho el propio narrador comentará sobre este complejo de Edipo: "Suzanne es la única forma de romper ese camino, de alejarse de su madre, de reemplazarla, al fin" (ibid.:33).

Sobre Suzanne también declarará: "será, en cierto sentido, la mujer más importante de su vida. No porque sea su alma gemela (...) a sus amigos acostumbrados a Peggy -la inteligencia, la ironía, el refinamiento, (...)-, Suzanne no les cae muy bien" (ibid.:32). Vemos que ni sus amigos entienden esta elección, otra incomprensión que suma a otras que mencionaremos más adelante.

Antes de pasar al siguiente capítulo, señalemos que es inevitable en un escritor tan paradigmático, con un estilo tan singular, que se relacionen hechos de su vida con su obra. No nos referimos al biografismo, donde se busca explicar la obra por los hechos de la vida del autor, sino a que la obra ilumina mejor algunos aspectos de lo vivido que otros. En este sentido, consideramos certera la elección de comenzar la novela con un incidente que posiblemente sea el más beckettiano de toda su vida. No sólo porque el dramaturgo fue acuchillado sin motivo, sino porque lo único que lamenta es el abrigo arruinado y, de hecho, Beckett pide al juez compensación por el abrigo (que 
es negada) y decide no presentar cargos. En la misma línea, vemos que, en determinada escena, el tiempo parece detenido, como en Esperando a Godot: "al otro día, o cien días después" (ibid.:13).

El segundo apartado intitulado "Enciclopedia Beckett" se compone de una cincuentena de breves fragmentos que dan un panorama más completo de la vida del autor de El innombrable. Por supuesto, estas entradas no están ordenadas alfabéticamente, sino cronológicamente, aunque con algunas prolepsis y analepsis -como sucedía en el primer capítulo-. En este capítulo, no faltará el humor. Por ejemplo, a través de la cita errada: "Intentando nuevamente dormir y fracasando otra vez (fracasando peor)" (EI subrayado es nuestro. ibid.:44). Pero también cuando señala la vanidad del autor de Ulíses: "Dante...Bruno.... Vico....Joyce, donde el 'Joyce' final es una sugerencia... del propio Joyce" (ibid.:50). No escatima su burla al propio protagonista, en un fragmento dedicado a su cuidado capilar: "Un pelo crespo, peinado hacia arriba y hacia atrás, corto a los costados, (...) y que en su vejez combinaba muy bien con su rostro de lagartija (...) y con las gafas (...) dándole el aspecto de un científico loco" (ibid.:67).

El tercer capítulo, cuyo título coincide con el de la obra La última cinta de Krapp, está dividido también en fragmentos, cada uno narrado por una mujer de la vida de Beckett ${ }^{1}$. Allí, como si de Rashomon se tratase, florecen las contradicciones entre las distintas versiones. Peggy habla mal de Suzanne y viceversa. Esto genera la sensación de que se trata de un personaje no del todo comprendido, ni siquiera por sus más allegadas: "Beckett siempre fue un enigma para mí” (ibid.:86).
La cuarta parte es la única que prioriza la obra por sobre la vida del irlandés. Se trata del apartado más ficcional y de menos interés para aquel que sólo busca información sobre Beckett. Allí se narra la historia de Felipe, un joven argentino que está obligado, por una materia del secundario, a leer Esperando a Godot y escribir sobre ella. Finalmente descubrirá temas que le resuenan en esa obra -que tan ajena le resultaba, a priori- puesto que encontrará un paralelo entre su madre (que espera el regreso del padre que los abandonó a ambos) con Vladimir y Estragón. Detrás de este apartado, subyace la idea de que los temas del escritor son tan universales que incluso los más insospechados lectores o espectadores podrán conectar con sus obras.

En el último apartado, similar al primero, Beckett vuelve a ser protagonista, ya viejo, se cae seguido; físicamente está muy desmejorado, su memoria lo engaña, en definitiva, se acerca más Hamm o Krapp. Paradójicamente, vemos la perplejidad de los trabajadores del geriátrico frente a que esa persona haya escrito esos textos y obtenido un premio Nobel.

Una frase del tercer capítulo, puesta en boca de Suzanne ("todo lo que se dice sobre Beckett es falso. Falso hasta los tuétanos. Beckett es mucho más y mucho menos de lo que se dijo y lo que se dirá de él") parece desmentir la posibilidad de conocer la vida interior del escritor y, por lo tanto, de entenderlo, aunque como vemos, en este libro a través de las contradicciones vistas y narradas podemos por lo menos atisbar algunas de sus complejidades (ibid.:84). Nos queda su obra que, como vimos en el cuarto capítulo, sigue esperando nuevos lectores y espectadores. 